\title{
Ictal/postictal SPECT in the pre-surgical localisation of complex partial seizures
}

\author{
Roderick Duncan, James Patterson, Richard Roberts, Donald M Hadley, Ian Bone
}

\begin{abstract}
Single photon emission computed tomography (SPECT) used in conjunction with HM-PAO (Ceretec-Amersham International) was used to image regional cerebral blood flow (rCBF) in 28 patients with medically intractable complex partial seizures during or soon after a seizure, and interictally. Changes from interictal rCBF were seen in $26 / 28(93 \%)$ patients. The main findings were; 1) During the seizure-hyperperfusion of the whole temporal lobe; 2) Up to $2 \mathrm{~m}$ postictallyhyperperfusion of the hippocampus with hypoperfusion of lateral temporal structures; 3) From 2-15m postictally-hypoperfusion of the whole temporal lobe. When compared with EEG and MRI data, correct locaiisation to one temporal lobe was obtained in 23 patients. In one further patient bilateral temporal foci, and in a further two patients frontal foci, were correctly identified. There were no disagreements between EEG and SPECT localisation. Temporal lobe surgery was successful (by the criterion of at least $\mathbf{9 0 \%}$ reduction in seizure frequency) in all but one of the 23 patients operated on. It is concluded that ictal/postictal SPECT is a reliable technique for the presurgical localisation of complex partial seizures. The data indicate a likely sequence of changes in rCBF during and after complex partial seizures of temporal lobe origin.
\end{abstract}

\section{(f Neurol Neurosurg Psychiatry 1993;56:141-148)}

Institute of

Neurological Sciences,

Southern General

Hospital, Govan Road,

Glasgow G51 4TF, UK.

$R$ Duncan

J Patterson

D M Hadley

I Bone

Department of

Medicine, Ninewells

Hospital and Medical

School, Dundee.

R Roberts

Department of

Neurology, Dundee

Royal Infirmary,

Dundee

Correspondence to:

Dr R Duncan

Received 23 January 1992

and in

27 March 1992.

Accepted 1 April 1992.

Temporal lobectomy is an accepted and effective treatment for complex partial seizures (CPS) of temporal lobe origin that are refractory to medical treatment. Even in affluent countries delivering comprehensive medical care, large numbers of patients are unable to benefit from this form of treatment because of the complex, expensive and time consuming presurgical assessment often necessary. ${ }^{1}$

Single photon emission computed tomography (SPECT) can be used in conjunction with Technetium $99 \mathrm{~m}$ labelled HM-PAO (Ceretec-Amersham International) to study regional cerebral blood flow (rCBF) during seizures or in the immediate postictal period, and the changes seen can be used to aid presurgical localisation of an epileptic focus. ${ }^{23}$ The use of ictal/postictal SPECT might therefore reduce the number of patients requiring invasive EEG monitoring, and so provide a way of making surgical treatment more widely available in the context of finite financial resources.

This study aimed to assess the value of SPECT in localising epileptic foci in a sequential series of presurgical patients with CPS. Results are compared with ictal and interictal scalp, sphenoidal and foramen ovale EEG recording, MRI, pathological findings and the outcome of surgery.

\section{Subjects}

The 28 subjects had poorly controlled CPS, some with additional secondary generalised tonic/clonic seizures, and had been assessed for suitability for surgical treatment. The CPS in all cases had clinical features suggesting temporal lobe involvement (for example, deja vu or abdominal aura, orofacial automatisms). Seizure frequencies are given in table 3 . The mean age of the subjects was 22.8 years (range 5-36). Fifteen were female, 13 male. All had full clinical assessment MRI, ictal and interictal EEG recording and neuropsychological assessment. On the basis of this, all have confident focus localisations and have either been accepted or rejected for temporal lobe surgery: 23 have been operated on, 2 are awaiting surgery and 3 have been rejected for temporal lobectomy as having bilateral seizure onsets or extratemporal origin for their seizures.

\section{Methods}

\section{SPECT imaging procedure}

HMPAO (Ceretec-Amersham International) ${ }^{4}$ is a lipophilic compound which enters brain venous injection, in a distribution corresponding to rCBF. Inside brain tissue it becomes hydrophilic, and cannot escape back across the blood-brain barrier into the bloodstream. Its distribution, and that of the Tc $99 \mathrm{~m}$ with which it is labelled, remains constant for several hours, no matter what further changes occur in rCBF. A scan carried out during this period produces an image of $\mathrm{rCBF}$ at the time of injection.

The HMPAO was reconstituted with $500 \mathrm{MBq}$ of $\mathrm{Tc} 99 \mathrm{~m}$, resulting in an effective dose equivalent to the patient of $8 \mathrm{mSv}$ per scan, making $16 \mathrm{mSv}$ for the whole study. Scanning was carried out within 2 hours of injection using a Strichmann 810 tomographic tissue substantially on first pass after intra- 
imager, producing $12 \mathrm{~mm}$ axial slices through the whole brain parallel to the orbitomeatal line, and through the temporal lobe parallel to its long axis [transaxial (TA) slices]. The software now used with the imager allows reconstruction of these images in any chosen plane including coronal, sagittal and axial, with any degree of tilt.

\section{Interictal SPECT}

Interictal scans were carried out more than 24 hours from the last reported seizure, except in 4 patients whose seizures were too frequent. The injections were given in a quiet room. The patients lay still with eyes shut during, and for 3 minutes after, the injection.

\section{Ictal/postictal SPECT}

Patients were admitted to the ward and had an intravenous cannula inserted. They waited in the ward day room under the observation of nursing staff. On witnessing a seizure, the nurse would note the time of the end of the stare, and notify the house officer who would then make up and give the HMPAO injection, again noting the time. Detailed descriptions of the seizures were recorded, from members of staff or patients witnessing the event and also from the patient. Scanning was carried out as soon as the patient was comfortable enough to go to the scanning room, in all cases within 2 hours.

\section{Reporting of SPECT images}

SPECT images were reported independently by three investigators ( $R D, J P$ and $D M H)$. Disagreements were resolved by consensus conference. Reporting was carried out blind to EEG and structural imaging data, but not to the diagnosis of complex partial epilepsy or the time since last seizure. The interictal and ictal/ postictal scans were regarded as two parts of the same investigation, and were therefore reported simultaneously, with the investigators aware of which was which.

An area was reported as abnormal if the uptake appeared above or below that expected for the area on at least 2 adjacent slices, limiting sensitivity to areas at least $2 \mathrm{~cm}$ thick. In the latest Strichmann software (supplied to our group for Beta testing) the 3 dimensional block of SPECT data can be re-sliced in any orientation allowing the effect of slice tilt to be assessed. Images were displayed using the nonlinear "Fire and Water" scale supplied with the system.

Numerical analysis of SPECT images

Quantitative analysis was performed by 2 investigators ( $R D$ and JP) on transaxial slices, at the level of the mid-temporal lobe, and the results averaged. Where an abnormality had been reported in the temporal lobe the slice reported as showing the greatest abnormality was analysed. The template used for defining mesial and lateral regions of interest (ROI) is illustrated in fig 1. Count density was calculated for each ROI, corrected for background counts and the asymmetry expressed as follows:
$\%$ asymmetry $=\frac{100 \times(\text { right }- \text { left }) /(\text { right }+ \text { left })}{2}$

\section{EEG}

In 22 patients the EEG assessments were carried out in Dundee Royal Infirmary by RR, who was blind to MRI and SPECT results, though not to the results of previous surface interictal EEG data. In addition to routine EEG recording all had seizures recorded during long term EEG monitoring with scalp and sphenoidal electrodes. In 17 cases in which the side and site of seizure onset remained uncertain further seizures were recorded with bilateral foramen ovale electrodes having either a single recording contact ( 8 cases) or 4 contacts $1 \mathrm{~cm}$ apart (9 cases). Four paediatric cases (patients 3, 18, 20 and 25) had interictal and ictal scalp EEG recordings at the Royal Hospital for Sick Children, Yorkhill, Glasgow. Two patients (1 and 24) had interictal and ictal scalp recordings at Quarrier's Homes, Bridge of Weir, Renfrewshire.

\section{$M R I$}

MRI was performed using a $0.15 \mathrm{~T}$ resistive magnet, producing T1 (IR 1600/40/400) and T2 weighted (SE 2000/80) axial images of the whole brain, and balanced and/or T2 weighted (SE 700/32, SE 2000/80) coronal images of the temporal lobes.

\section{Results}

\section{Interictal findings}

Each of the 28 patients had one interictal scan. The time since last reported seizure was more than 24 hours in 24 patients (range 24 hours12 days), 12-24 hours in 3 patients. The remaining patient had been injected before it was realised that he had had a seizure 2 hours earlier. While this was not truly interictal, it

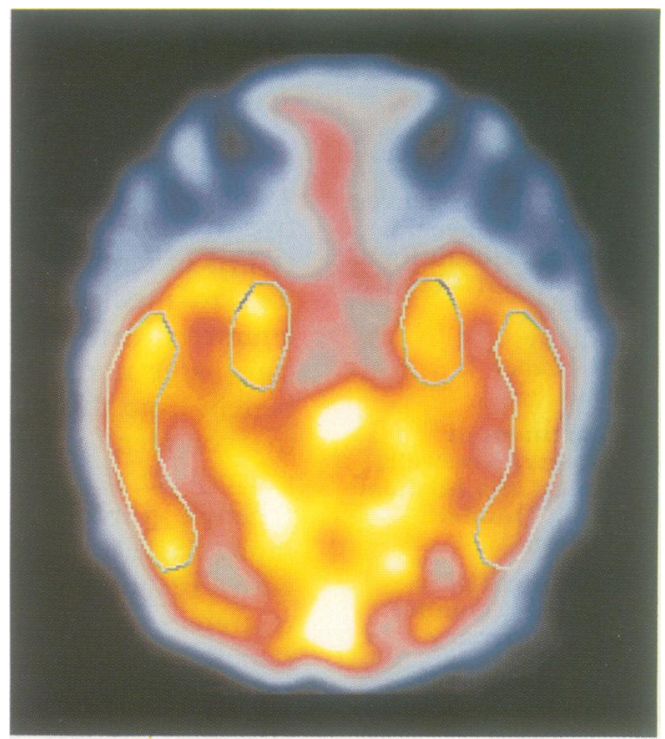

Figure 1 Transaxial temporal lobe slice illustrating mesial and lateral regions of interest used for numerical analysis of images. 
Table 1 Interictal $r C B F$ in 28 patients (15 abnormal)

\begin{tabular}{lll}
\hline Hypoperfusion $(n=13)$ & Hyperperfusion $(n=1)$ & Both $(n=1)$ \\
\hline $\begin{array}{l}\text { Unilateral temporal-10 } \\
\text { Bilateral temporal-1 } \\
\text { Temporal + frontal-2 }\end{array}$ & $\begin{array}{l}\text { Lateral temporal } \\
\text { hyperperfusion }\end{array}$ & $\begin{array}{l}\text { Mesial temporal hyperperfusion } \\
\text { with lateral hypoperfusion }\end{array}$ \\
\hline
\end{tabular}

showed resolution of his immediate postictal changes and was not repeated.

Interictal $\mathrm{rCBF}$ was reported visually as abnormal in 15 patients (54\%). The findings were used as a baseline for interpreting ictal/ postictal scans, and are summarised in table 1 . The results exclude focal hypoperfusion seen in 2 patients, accounted for by anatomical lesions seen on MRI.

\section{Ictal/postictal changes}

The timing of ictal/postictal injections ranged from during the seizure to 1.5 hours after. Eight injections were carried out during the seizure, 14 within 2 minutes of the end of the seizure, 5 within 15 minutes and 1 at 1.5 hours. One injection was during a secondary generalised seizure, the rest during or after complex partial seizures.

Based on visual reporting, changes in $\mathrm{rCBF}$ from the interictal scan were seen in $26 / 28$ (93\%) patients. This includes 2 patients who had unilateral temporal hypoperfusion interictally and showed resolution of their abnormality ( $1 \mathrm{~m}$ and $30 \mathrm{~s}$ ) postictally.

The changes in perfusion seen during and soon after seizures are summarised in table 2 . Most fell into 3 basic patterns:

1 Hyperperfusion of the whole temporal lobe (fig 2). This was seen in 5 patients, all injected during the seizure.

2 Hyperperfusion of the hippocampus with hypoperfusion of the lateral temporal lobe, which often extended to involve the whole ipsilateral hemisphere (fig 3). This was seen in 11 patients, bilaterally in 2 of these, and combined with an area of hypoperfusion in the contralateral parietal lobe in 1 . One of these patients (patient 15) was injected during a secondary generalised seizure, the rest up to 2 minutes from the end of complex partial seizures.

Patients in whom hippocampal perfusion was symmetric, but was preserved relative to hypoperfused perfusion lateral temporal structures are included in this group, as is one patient who had hippocampal hyperperfusion without appreciable hypoperfusion of lateral structures.

Table 2 Summary of postictal changes and their timing

\begin{tabular}{|c|c|c|}
\hline $\begin{array}{l}\text { Number of patients showing change } 26 / 28 \\
\text { Type of change }\end{array}$ & Number of patients & $\begin{array}{l}\text { Time after end of } \\
\text { seizure }(O=\text { ictal })\end{array}$ \\
\hline $\begin{array}{l}1 \text { Hyperperfusion of whole } \\
\text { temporal lobe }\end{array}$ & 5 & 0 \\
\hline $\begin{array}{l}2 \text { Hyperperfusion of mesial temporal area } \\
\pm \text { hypoperfusion in ipsilateral temporal lobe }\end{array}$ & 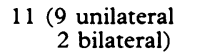 & \\
\hline 3 Hypoperfusion only & 5 & $30 \mathrm{~s}-15 \mathrm{~m}$ \\
\hline $\begin{array}{l}4 \text { Hyperperfusion with contralateral hypoperfusion } \\
\text { (includes both patients with frontal changes) }\end{array}$ & 4 & $0-9 \mathrm{~m}$ \\
\hline $\begin{array}{l}5 \text { Resolution of temperal hypoperfusion } \\
6 \text { No change }\end{array}$ & $\begin{array}{l}2 \\
2\end{array}$ & $\begin{array}{l}30-60 \mathrm{~s} \\
0 \text { and } 10 \mathrm{~m}\end{array}$ \\
\hline
\end{tabular}

NB patient 6 falls into 2 of the above categories

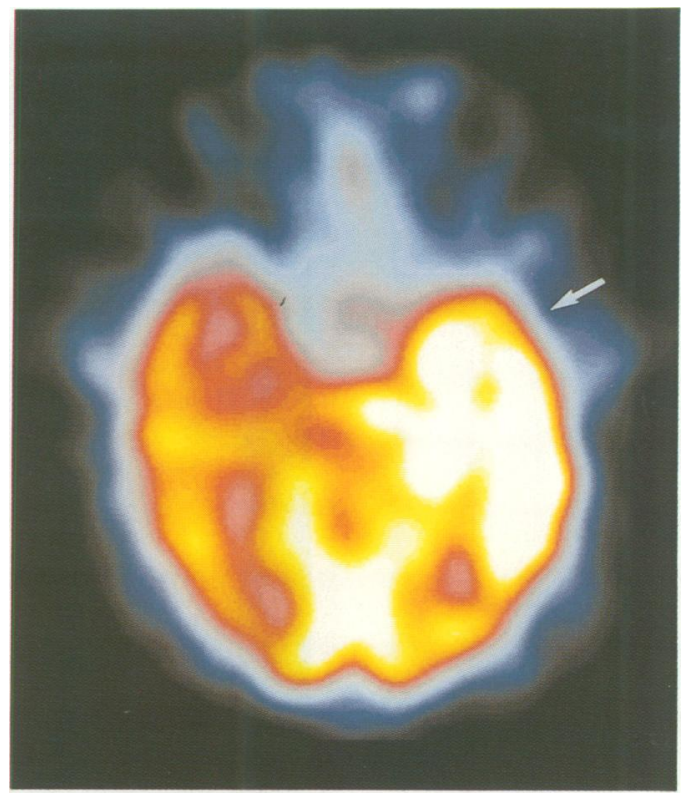

Figure 2 Transaxial temporal lobe slices: patient 11 (type 1 change-see text). Scan following injection during a complex partial seizure showing hyperperfusion of the whole of the left temporal lobe (arrow).

3 Hypoperfusion of the temporal lobe (fig 4). This was seen in 5 patients, injected at 30 s ( 2 patients), $4 \mathrm{~m}$ and $15 \mathrm{~m}$. It involved the whole temporal lobe in 2 patients, and extended in lesser degree into the ipsilateral frontal lobe in 2 patients. One patient included in this group had hypoperfusion which involved the mesial temporal lobe only.

These patterns are illustrated in fig 5, and account for changes seen in all but 6 patients, including 2 who were eventually shown to have frontal foci:

In 4 of these there was hypoperfusion contralateral to hyperperfusion. In 2 this involved the frontal lobes (patients 14 and 22;

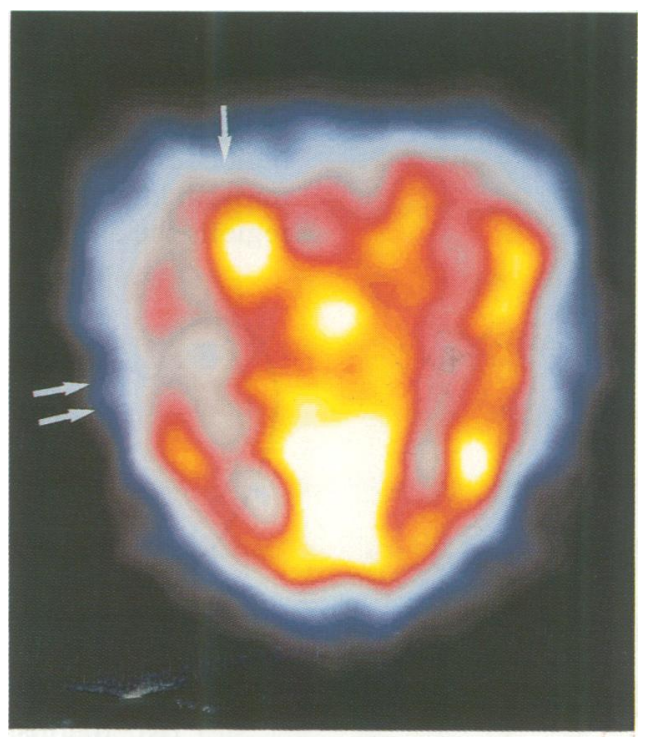

Figure 3 Transaxial temporal lobe slices; patient 25 (type 2 change-see text). Scan following injection 1 minute after a complex partial seizure showing hyperperfusion of the right medial temporal cortex (arrow) with hypoperfusion of the lateral cortex (arrows). 


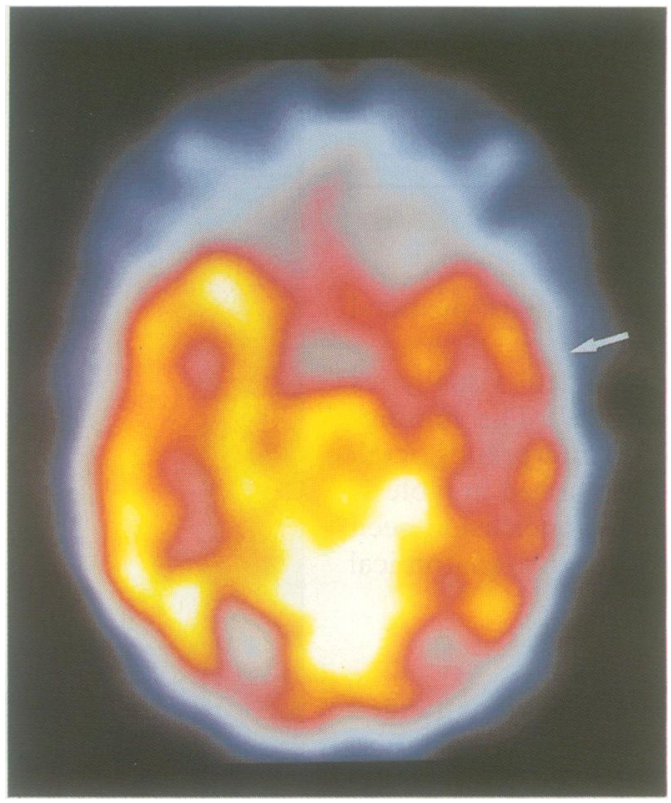

Figure 4 Transaxial temporal lobe slices: patient 12 (type 3 change-see text). Scan following injection 4 minutes after a complex partial seizure showing hypoperfusion of the medial and lateral temporal cortex (arrow).

fig 6). One patient (patient 2) had hyperperfusion of the posterior temporal and occipital areas with hypoperfusion of most of the contralateral hemisphere. One patient (patient 6) showed pattern 2 in one temporal lobe with a small area of hypoperfusion in the contralateral parietal lobe.

Two patients (patients 5 and 10) had hypoperfusion interictally, but a normal postictal scan.

Two patients, both with abnormal interictal rCBF, showed no change (patients 19 and 28, injected $10 \mathrm{~m}$ postictally and during the seizure, respectively).

\section{Numerical analysis of images}

The main brain areas of interest were the temporal lobes, and data from mesial and lateral temporal ROIs are presented in fig 7. Not surprisingly, there was no case in which numerical data disagreed in direction with visual interpretation. The asymmetry in regions reported as normal ranged from $0-7 \%$ for both lateral and mesial ROIs. For abnormal regions the asymmetry ranged from $7-51 \%$ for mesial regions and $7-58 \%$ for lateral regions. Asymmetry indices were greater in the lateral ROI postictally than in the other 3 groups, (see fig 7), whether the whole group or only the abnormal values $(p<0.001$ and $p<0.01$ respectively, using the Mann Whitney test) were compared.

Correlation of SPECT with EEG, MRI and operative results

Individual SPECT, MRI, EEG pathological and operative results are given in Table 3.

Twenty three patients have been operated on, and 2 have completed their investigations and are on the waiting list. Twenty two patients had anterior temporal lobectomy, and one had removal of a tumour from the anterior temporal lobe. Three patients were not offered operation because investigations indicated a frontal origin for their seizures (patients 14 and 22) or bilateral independent temporal foci (patient 15).

In operated patients, the follow up period ranges from 5-36 (median 16) months. Sixteen patients are seizure free (follow up period 8-36 months). One of these patients (patient 10) had one seizure post operatively, but has been seizure free for 14 months since, and one (patient 12) had several auras during an attack of viral meningitis three months postoperatively but has now been seizure free for 11 months. Five patients have more than $90 \%$ reduction in seizure frequency, and one has auras but no seizures. The remaining patient has had only a $40 \%$ reduction in seizure frequency.

Correct localisation (as judged by agreement of the results of EEG, MRI and surgery) to one lobe was provided by interictal SPECT in 13 patients. When the results of ictal/postictal SPECT were also taken into account, correct localisation to one lobe was provided in 22 patients (this includes patient 6 , in whom the perfusion disturbance in the pariental lobe contralateral to the focus was relatively minor). In a further 3 patients, extratemporal origin for seizures or bilateral temporal foci were correctly identified.

Of the remainder, one patient (patient 16) showed bilateral SPECT changes (pattern 2), while EEG and MRI suggested a unilateral temporal focus, and two patients ( 2 and 28 )

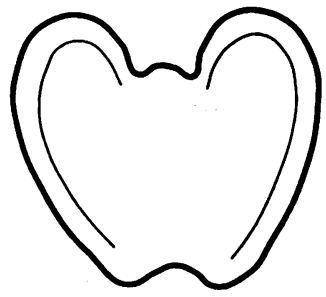

Interictal

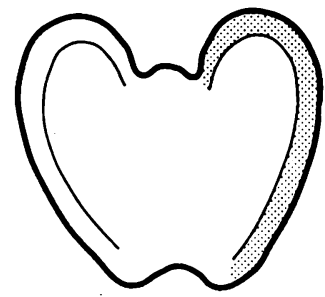

Ictal

Hyperperfusion

Hypoperfusion

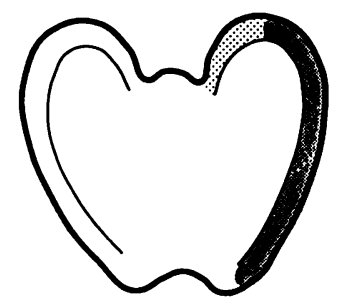

0-2 m

Postictal

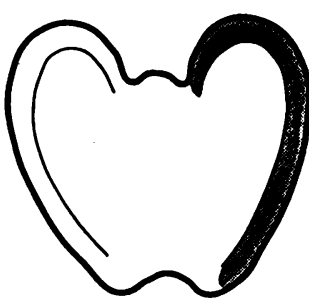

2-15 m

Postictal

Figure 5 Possible sequence of changes in $r C B F$ during and after seizures of temporal lobe origin. The diagram illustrates changes in the transaxial orientation. Left to right: normal rCBF, hyperperfusion of the whole temporal lobe, hyperperfusion of the medial temporal cortex with lateral hypoperfusion, hypoperfusion of the whole temporal lobe. 
Figure 6 Orbitomeatal slices: patient 14. Left: Interictal scan showing normal $r C B F$. Right: Scan following injection 2 minutes after a complex partial seizure showing hyperperfusion of the right frontal cortex (arrow) and hypoperfusion of the contralateral frontal cortex.
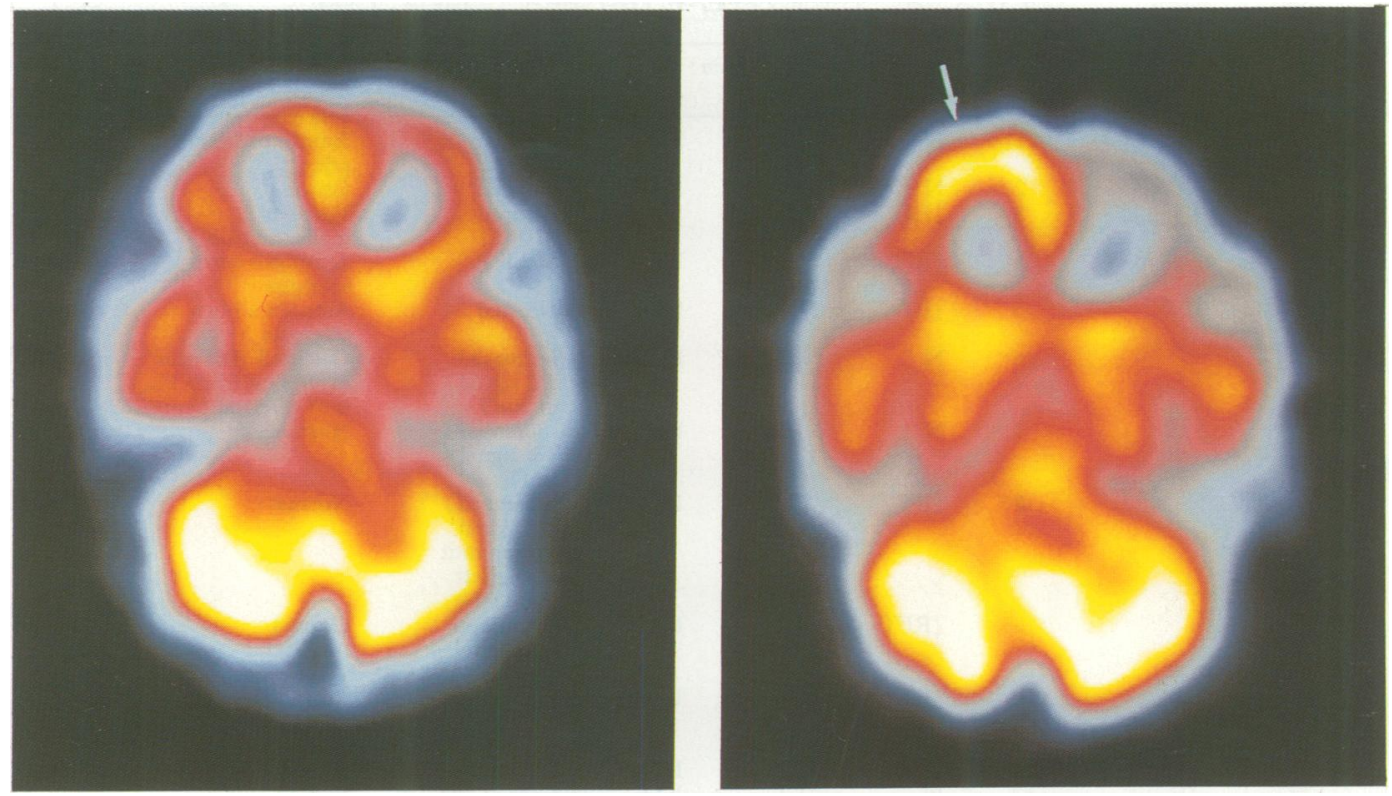

had findings which lateralised correctly, but were not localised to one lobe (albeit the perfusion disturbance was maximal in the correct lobe in each case). There were no patients in whom SPECT falsely localised.

\section{Discussion}

Ictal or postictal rCBF has been studied in small numbers of patients with PET or with SPECT using 123I labelled amines. ${ }^{5-8}$ Both methods have the theoretical disadvantage of protracted tracer accumulation. The image given by I-123 HIPDM, for example, reflects $75 \%$ of uptake over the first 2 minutes after injection and $25 \%$ over a further 30 minutes. The largest of these studies ${ }^{8}$ featured 34 patients, SPECT localising correctly (as judged by EEG and surgical results) in $93 \%$, with no false localisations.

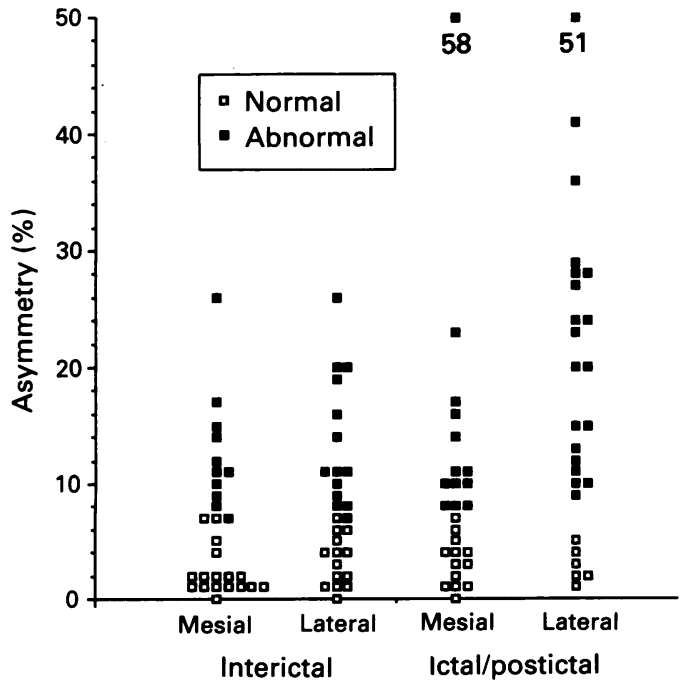

Figure 7 Scattgram showing absolute percentage asymmetry in mesial and lateral regions of interest, for both interictal and ictal/postictal scans. The open symbols represent those regions reported visually as normal and the closed ones those reported as abnormal.
The development of Tc99m HMPAO has provided a more precise (in terms of temporal resolution) and more convenient (in terms of radionuclide availability) method of imaging ictal/postictal $\mathrm{rCBF}$, and Rowe et $a l^{23}$ were able to obtain postictal images in two series of 32 and 51 patients, localising correctly in $72 \%$ and $69 \%$ respectively. They concluded that postictal SPECT was a practical and reliable method of seizure localisation in the majority of patients undergoing evaluation for temporal lobectomy. Our own experience has been similar. We were able to obtain ictal or postictal SPECT in 28 patients with a mean time of admission of 6.6 days (range 1-25 days), including time to reduce and re-establish medication where necessary. A useful result (either correct localisation or identification of extratemporal or bilateral seizure origin) was obtained in $26 / 28$ (93\%). This higher proportion may have been due to the fact that this study included only those patients in whom firm localisation had been obtained using MRI and our relatively non-invasive EEG workup; in our total series of patients who have had ictal/postictal SPECT (unpublished data), $75 \%$ show localising changes.

Quantitation of SPECT images can be

1 Absolute-where the absolute value of cerebral blood flow is determined

2 Normalised-where the ratio of tracer uptake in any region is normalised to that of a reference region.

3 Quantitation of asymmetry - where the ratio between corresponding left and right regions is calculated.

Although there are experimental techniques for obtaining absolute measurements of blood flow using HMPAO SPECT, there is currently no reliable method usable in the clinical setting. Normalised data have been used but, even using the average count from the whole brain as a reference (theoretically a better option than using any one part of the brain), this has been found to be unreliable on the carried out in three ways: 
Table 3 Correlation of SPECT, MRI, EEG, pathological findings and operative results

\begin{tabular}{|c|c|c|c|c|c|c|c|c|}
\hline Patient & $\begin{array}{l}\text { SPECT } \\
\text { Interictal }\end{array}$ & $\begin{array}{l}\text { Localisation } \\
\text { Postictal }\end{array}$ & $E E G$ & $\begin{array}{l}M R I \\
\text { findings }\end{array}$ & $\begin{array}{l}\text { Pathological } \\
\text { findings }\end{array}$ & $\begin{array}{l}\text { Operative date } \\
\text { and result }\end{array}$ & $\begin{array}{l}\text { Pre-op sei } \\
\text { absences }\end{array}$ & $\begin{array}{l}\text { izures/month: } \\
\text { generalised }\end{array}$ \\
\hline 1 & $\mathbf{N}$ & $\uparrow \mathrm{LmT}$ & LT & Normal & $\begin{array}{l}\text { Ammon's horn } \\
\text { sclerosis }\end{array}$ & $1 / 89, \mathrm{SF}$ & 8 & 0 \\
\hline $\begin{array}{l}2 \\
3\end{array}$ & $\begin{array}{l}\mathbf{N} \\
\downarrow \mathbf{L T}\end{array}$ & $\begin{array}{l}\uparrow \mathrm{RH} \downarrow \mathrm{LH} \\
\downarrow \downarrow \mathrm{LFT}\end{array}$ & $\begin{array}{l}\text { RpT } \\
\text { LT }\end{array}$ & $\begin{array}{l}\text { Normal } \\
\text { Atrophy }\end{array}$ & $\begin{array}{l}\text { Gliosis } \\
\text { Vascular } \\
\text { malformation }\end{array}$ & $\begin{array}{l}4 / 89,>90 \\
5 / 89, \text { SF }\end{array}$ & $\begin{array}{l}13 \\
80\end{array}$ & $\begin{array}{l}1 \\
0\end{array}$ \\
\hline 4 & $\uparrow \mathbf{R I T}$ & $\downarrow \uparrow R T$ & RT & Small R & $\begin{array}{l}\text { Ammon's horn } \\
\text { sclerosis }\end{array}$ & $6 / 89, \mathrm{SF}$ & 10 & 1 \\
\hline 5 & $\downarrow \mathbf{L T}$ & $\mathbf{N}$ & $\mathbf{L T}$ & Normal & $\begin{array}{l}\text { Ammon's horn } \\
\text { sclerosis }\end{array}$ & 9/89, SF & 55 & 0 \\
\hline 6 & $\mathbf{N}$ & $\uparrow \downarrow R T \downarrow L P$ & $\mathrm{RmT}^{\star}$ & $\begin{array}{l}\text { Increased } \\
\text { T2 signal } \\
\text { in } R \mathbf{m T}\end{array}$ & $\begin{array}{l}\text { Calcified glial scar } \\
\text { extending from TL } \\
\text { into cerebral peduncle }\end{array}$ & $10 / 89$, SF & 250 & 5 \\
\hline 7 & $\mathbf{N}$ & $\uparrow \downarrow \mathbf{L T}$ & $\mathrm{LmT}^{\star}$ & $\begin{array}{l}\text { Increased } \\
\text { T2 signal } \\
\text { LmT }\end{array}$ & Normal & $11 / 89, \mathrm{SF}$ & 35 & 0 \\
\hline 8 & $\downarrow$ BT & $\downarrow \downarrow L T$ & $\mathrm{LT}^{\star}$ & $\begin{array}{l}\text { Increased } \\
\text { T2 signal } \\
\text { throughout } \\
\text { whole left } \\
\text { temp.lobe }\end{array}$ & Normal & $1 / 90,>90$ & 68 & 0 \\
\hline 9 & $\downarrow$ RFT & $\uparrow \downarrow R T$ & $\mathrm{RT}^{\star}$ & $\begin{array}{l}\text { Glioma in } \\
\text { right mid } \\
\text { TL }\end{array}$ & Glioma & $2 / 90, \mathrm{SF}$ & 35 & 2 \\
\hline 10 & $\downarrow \mathbf{L T}$ & $\mathbf{N}$ & $\mathrm{LmT}^{\star}$ & $\begin{array}{l}\text { Increased } \\
\text { T2 signal } \\
\text { LmT }\end{array}$ & $\begin{array}{l}\text { Ammon's horn } \\
\text { sclerosis }\end{array}$ & $3 / 90, \mathrm{SF}$ & 8 & 1 \\
\hline $\begin{array}{l}11 \\
12\end{array}$ & $\underset{\mathbf{N}}{\downarrow \mathbf{L T} T}$ & †LT & $\begin{array}{l}\mathbf{L T}^{\star} \\
\mathbf{L T}^{\star}\end{array}$ & $\begin{array}{l}\text { LT atrophy } \\
\text { Cyst at left } \\
\text { temp.pole }\end{array}$ & $\begin{array}{l}\text { Gliosis } \\
\text { Benign cyst }\end{array}$ & $\begin{array}{l}5 / 90,>90 \\
8 / 90, \mathrm{SF}\end{array}$ & $\begin{array}{l}65 \\
30\end{array}$ & $\begin{array}{l}5 \\
0\end{array}$ \\
\hline 13 & $\downarrow R T$ & $\uparrow \downarrow R T$ & $\mathrm{RmT}^{\star}$ & Normal & $\begin{array}{l}\text { Ammon's horn } \\
\text { sclerosis }\end{array}$ & $8 / 90,40$ & 15 & 1 \\
\hline 14 & $\mathbf{N}$ & $\uparrow \mathbf{R F} \downarrow \mathbf{L F}$ & NL & $\begin{array}{l}\text { Long T1 T2 } \\
\text { lesion RFL }\end{array}$ & $\begin{array}{l}\text { No op. } \\
\text { (frontal) }\end{array}$ & & 33 & 5 \\
\hline 15 & $\downarrow$ LT & $\uparrow \downarrow \mathbf{B T}$ & $\mathrm{BmT}^{\star}$ & Normal & $\begin{array}{l}\text { No op. } \\
\text { (bilateral) }\end{array}$ & & 10 & 2 \\
\hline 16 & $\mathbf{N}$ & $\uparrow \downarrow \mathrm{BT}$ & $\mathrm{LmT}^{\star}$ & $\begin{array}{l}\text { Long T1 T2 } \\
\text { lesion }\end{array}$ & Normal & $1 / 91>90$ & 12 & 1 \\
\hline 17 & $\downarrow \mathbf{L T}$ & $\uparrow \mathbf{L T}$ & $\mathrm{LmT}^{\star}$ & Normal & Gliosis & $\begin{array}{l}4 / 91 \text {,Auras } \\
\text { only }\end{array}$ & 10 & 1 \\
\hline $\begin{array}{l}18 \\
19\end{array}$ & $\begin{array}{l}\mathrm{N} \\
\uparrow \downarrow L T\end{array}$ & $\begin{array}{l}\downarrow \mathbb{R m T} \\
\uparrow \downarrow \mathbf{L T}\end{array}$ & $\begin{array}{l}\mathrm{RT} \\
\mathrm{LmT}^{\star}\end{array}$ & $\begin{array}{l}\text { Normal } \\
\text { Long T2 } \\
\text { lesion LmTL }\end{array}$ & $\begin{array}{l}\text { Inflammatory } \\
\text { AVM }\end{array}$ & $\begin{array}{l}5 / 91, \text { SF } \\
5 / 91, \text { SF }\end{array}$ & $\begin{array}{l}25 \\
15\end{array}$ & $\begin{array}{l}1 \\
0\end{array}$ \\
\hline 20 & $\downarrow \mathbf{L T}$ & $\downarrow \downarrow L T$ & LT & $\begin{array}{l}\text { Long T2 } \\
\text { lesion LmTL }\end{array}$ & $\begin{array}{l}\text { Ammon's horn } \\
\text { sclerosis }\end{array}$ & $5 / 01, \mathrm{SF}$ & 34 & 0 \\
\hline 21 & $\downarrow$ LT & $\uparrow \mathbf{L T}$ & $\mathrm{LmT}^{\star}$ & Normal & $\begin{array}{l}\text { Ammon's horn } \\
\text { sclerosis }\end{array}$ & $5 / 91, \mathrm{SF}$ & 28 & 1 \\
\hline 22 & $\mathbf{N}$ & $\uparrow \mathrm{RF} \downarrow \mathrm{LF}$ & RF & $\begin{array}{l}\text { Long T1 } \\
\text { lesion RFL }\end{array}$ & $\begin{array}{l}\text { No op. } \\
\text { (frontal) }\end{array}$ & & 64 & 4 \\
\hline 23 & $\mathbf{N}$ & $\uparrow \downarrow \mathbf{L T}$ & $\mathrm{LmT}^{\star}$ & $\begin{array}{l}\text { Long T2 } \\
\text { lesion LmTL }\end{array}$ & Normal & $6 / 91, \mathrm{SF}$ & 48 & 0 \\
\hline 24 & $\downarrow$ LT & $\uparrow \downarrow \mathbf{L T}$ & LT & $\begin{array}{l}\text { Long T2 } \\
\text { lesion } \mathrm{LmTL}\end{array}$ & Normal & $8 / 91, \mathrm{SF}$ & 30 & 0 \\
\hline $\begin{array}{l}25 \\
26 \\
27 \\
28\end{array}$ & $\begin{array}{l}\mathbf{N} \\
\downarrow \mathbb{R T} \\
\mathbf{N} \\
\downarrow \text { RFT }\end{array}$ & $\begin{array}{l}\uparrow \downarrow R T \\
\uparrow R T \\
\uparrow R T \\
\downarrow R F T\end{array}$ & $\begin{array}{l}\mathrm{RT} \\
\mathrm{RmT}^{\star} \\
\operatorname{RmT}^{\star} \\
\operatorname{RmT}^{\star}\end{array}$ & $\begin{array}{l}\mathbf{N} \\
\mathbf{N} \\
\mathbf{N} \\
\text { Normal }\end{array}$ & $\begin{array}{l}\text { Inflammatory } \\
\text { MTS } \\
\text { Waiting list } \\
\text { Waiting list }\end{array}$ & $\begin{array}{l}9 / 91>90 \\
9 / 91, \text { SF }\end{array}$ & $\begin{array}{r}24 \\
12 \\
28 \\
8\end{array}$ & $\begin{array}{l}2 \\
1 \\
0 \\
1\end{array}$ \\
\hline
\end{tabular}

, increased flow; $\downarrow$, decreased flow; $\downarrow \downarrow$, markedly decreased flow; $\uparrow \downarrow$, increased hippocampal flow with decreased flow laterally; R, right; L, left; B, bilateral; T, temporal; F, frontal; P, parietal; H, hemisphere; L, lobe; 1, lateral; m, medial; NL, not localised; , foramen ovale recordings performed.

$>90$, greater than $90 \%$ reduction in seizure frequency; SF, seizure free.

individual level, by ourselves (unpublished data) and others. ${ }^{39}$ DiChiro and Brooks ${ }^{10}$ describe the limitations of image quantitation, even using a fundamentally quantitative technique such as positron emission tomography (PET).

We have used the third option, that of quantifying asymmetries in count density. We have used this method to define our reporting practice numerically, and produce figures which can be compared with those of other centres. The data show that visually we report asymmetries of $8 \%$ and more as abnormal. This is in accordance with normal data presented in our own previous work, ${ }^{11}$ and with the normal data presented by Rowe et al, ${ }^{9}$ (for example, normal variation in mesial ROI $-10 \%$ to $+8 \cdot 1 \%$ ). The abnormality rate in interictal scans in this study (53\%) is similar to those in earlier series from Glasgow ${ }^{1-13}$ and, given the relatively small numbers involved, comparable with that found by Rowe et al (45\%). ${ }^{9}$

There were no false localising abnormalities in interictal scans in this series, although one patient (patient 15) with unilateral temporal hypoperfusion interictally had independent left and right medial temporal seizure onsets (and bilateral medial temporal hyperperfusion on the ictal SPECT image). Interictal SPECT series reporting abnormalities in higher proportions of patients do tend to show frequent disagreements with EEG localisation. ${ }^{14-16}$ It is possible that this difference results from our more conservative reporting practice, an approach we advocate strongly. Since the results of SPECT may be used to guide a surgical resection, every effort should be made to ensure that the false positive rate is negligible, even though this means reporting localising abnormalities in a smaller proportion of patients. Further, there may be a slight increase in HMPAO uptake in the right over the left hemisphere, ${ }^{14}{ }^{17}$ underlining the need for cautious interpretation of small asymmetries.

This study demonstrates the main types of change in $\mathrm{rCBF}$ seen during or soon after seizures of temporal lobe origin, and suggest 
that patterns 1, 2 and 3 as shown in fig 5 occur in progression, a scheme compatible with the findings of Rowe et $a l^{23}$ We were unable to record the EEG concurrent with HMPAO injection, so it was necessary to settle for the potentially less accurate method of timing seizures clinically to the end of the "stare" phase of the complex partial seizure rather than to electrically recorded seizure onsets. Nethertheless, the timing of the changes we have seen is similar to that in the studies of Rowe et $a l^{2}$ where EEG timing was used, for example, pattern 2 being seen in patients injected within 5 minutes of seizure onset, as compared with up to 2 minutes from the end of the seizure in our study.

The two patients who showed partial resolution of unilateral temporal hypoperfusion on postictal scans might also fit in. It is possible that a near normal scan represents a transitional stage between hyperperfusion of the whole temporal lobe and postictal hypoperfusion. While in most cases the medial structures appear to remain hyperperfused longest, in some patients perfusion of the temporal lobe might reduce more uniformly.

Two groups of patients who did not fit into the above scheme are those who showed no change postictally, and those who showed hypoperfusion on one side and hyperperfusion on the other. Both patients with frontal foci were in this latter group. Both had confirmatory evidence of seizure origin in the hyperperfused frontal lobe, and since completing this series two further patients with CPS of frontal origin have shown this pattern. The issue of whether ictal/postictal SPECT can differentiate between CPS of frontal origin and those of temporal origin has yet to be adequately addressed, but these patients and the limited data available in the literature ${ }^{18}$ are encouraging in this respect.

Two other patients showed bilateral and opposite changes. In one (patient 6), parietal hypoperfusion was contralateral to the typical pattern of lateral hypoperfusion and medial hyperperfusion, the latter change being the major one and confirmed as the site of the focus. In the other (patient 2) most of the right hemisphere was hyperperfused, with widespread hypoperfusion contralaterally. The site of the focus was confirmed as being in the posterior part of the temporal lobe on the hyperperfused side, where hyperperfusion was maximal. This scan was carried out following injection very late after a series of complex partial seizures. This was done faute de mieux, as the patient tended to have seizures in the early morning when isotope was not available. Whether these changes were due to the preceding seizures, or were unconnected remains open to debate. Hyperperfusion of the lateral cortex is seen interictally in some patients, ${ }^{1-1319}$ and may not persist on rescanning, even if the time since the last seizure is similar and seizure control has not altered. ${ }^{11}$ The above may therefore represent a chance interictal finding.

In the two patients showing bilateral hippocampal hyperperfusion postictally (patients
15 and 16) foramen ovale recordings showed almost immediate spread of the discharge from whichever temporal lobe it originated into the contralateral temporal lobe. By contrast, in patient 2 the seizure discharge consistently started in the left temporal lobe, spreading to the right 1 minute later. The injection of HMPAO was carried out 4 minutes after the end of a seizure, but still localised to the temporal lobe in which the seizure originated. There would therefore appear to be some circumstances in which SPECT will show spread of seizure activity and some in which it will not. This issue requires further elucidation.

At one other centre ictal/postictal SPECT has reduced the proportion of its patients requiring invasive monitoring. ${ }^{23}$ This study, while supporting the use of ictal/postictal SPECT as a localising investigation, does not include patients who required depth studies, and so does not directly address the problem of whether SPECT can be used to replace them.

\section{Conclusion}

Our results show that ictal/postictal SPECT is reliable in the presurgical localisation of complex partial seizures, in terms of localising the seizure origin to one temporal lobe and possibly in terms of identifying CPS of extratemporal origin. Our data concur with previous studies in showing the sequence and timing of changes in rCBF during and after CPS of temporal origin. Ictal/postictal studies are essential to improve the sensitivity of SPECT and to link changes in $\mathrm{rCBF}$ to clinical seizure manifestations.

The SPECT imager used in this study was funded by the Wellcome Trust.

1 Leading article. Surgery for temporal lobe epilepsy. Lancet 1988;11:1115-16.

2 Rowe CC, Bercovic SF, Sia STB, et al. Localisation of epileptic foci with postictal single photon emission computed tomography. Ann Neurol 1989;26:660-8.

3 Rowe CC, Bercovic SF, Austin M, McKay WJ, Bladin PF. Patterns of postictal cerebral blood flow in temporal lobe epilepsy: qualitative and quantitative findings. Neurology 1991;41:1096-03.

4 Neirinckx RD, Canning LR, Piper IM, et al. Technetium 99m d,1-HM-PAO: a new radiopharmaceutical for SPECT imaging of regional cerebral blood perfusion. $\mathcal{f}$ Nucl Med 1987;28:191-202.

5 Franck G, Sadzot B, Salmon E et al. Regional cerebral blood flow and metabolic rates in human focal epilepsy and status epilepticus. In: Delgado-Escueta AV, et al, eds. status epileptic netrolo Advances in

6 Lee BI, Markand ON, Siddiqui AR, et al Single photon emission computed tomography (SPECT) brain imaging
using $\mathbf{N}, \mathbf{N}, \mathrm{N}^{\prime}$-trimethyl-N'-(2 hydroxy-3-methylusing N,N,N'-trimethyl-N'-(2 hydroxy-3-methyl(HIPDM): intractable complex partial seizures. Neurology (HIPDM): intract

7 Lee BI, Markand ON, Wellman HN, et al. HIPDM SPECT in patients with medically intractable complex partial seizures. Arch Neurol 1988;45:397-402.

8 Shen W, Lee BI, Park HM, et al. HIDPM-SPECT brain imaging in the presurgical evaluation of patients with intractable seizures. $\mathcal{F}$ Nucl Med 1990:31:1280-4.

9 Rowe CC, Berkovic SF, Austin MC, et al. Visual and quantitative analysis of interictal SPECT with technetium $99 \mathrm{~m} \mathrm{HMPAO}$ in temporal lobe epilepsy. $₹ \mathrm{Nucl} \mathrm{Med}$ 1991;32:1688-94.

10 DiChiro G, Brooks RA. PET quantitation, blessing and curse. I Nucl Med 1988;29:1603-4.

11 Duncan R, Patterson J, Bone I, Wyper DJ, McGeorge AP. Tc99m HMPAO single photon emission computed tomography in temporal lobe epilepsy. Acta Neurol Scand 1990;81:287-93. 
12 Duncan R, Patterson J, Hadley DM, et al CT, MR and SPECT imaging in temporal lobe epilepsy. $\mathcal{f}$ Neurol Neurosurg Psychiatry 1990;53:11-15.

13 Duncan R, Patterson J, Hadley DM, Bone I, W/yper D. SPECT in temporal lobe epilepsy: ictal and interictal studies. Current problems in epilepsy, vol 6. London: Libbey. 1990.

14 Valmier J, Touchon J, Daures P, Zanca M, Baldy-Moulinier $M$. Correlations between cerebral blood flow variations and clinical parameters in temporal lobe epilepsy: an interictal study. F Neurol Neurosurg Psychiatry 1987;50:

15 Valmier J, Touchon J, Baldy-Moulinier M. Interictal regional cerebral blood flow during non specific activation test in partial epilepsy. $\mathcal{f}$ Neurol Neurosurg Psychiatry
1989;52:364-71.

16 Biersack HJ, Stefan H, Reichman K. Brain imaging with $99 \mathrm{mTc}$-HMPAO SPECT, CT and NMR-results in 99mTc-HMPAO SPECT, CT and

17 Podreka I, Lang W, Suess E, et al Hexamethyl-propyleneamine-oxime (HMPAO) single photon emission computed tomography (SPECT) in epilepsy. Brain topography

18 Stefan H, Bauer J, Feistel H, et al. Regional cerebral blood flow during focal seizures of temporal and frontocentral onset. Ann Neurol 1990;27:162-6.

19 Grasso E, Ambrogio L, Cognazzo A, et al. Single photon emission computed tomography with $99 \mathrm{mTc}$ HMPAO in the study of focal epilepsy. Ital $\mathcal{f}$ Neurol Sci 1989;10: 175-9.

\section{Neurological stamp}

\section{Hermann Boerhaave 1668-1738}

Hermann Boerhaave was the outstanding physician and teacher of his time. At Leyden he introduced bedside teaching in his 12 bed hospital. He also introduced the thermometer and the value of urine examination in clinical practice. He was the first to isolate urea, describe the sweat glands and to establish that smallpox was spread only by contact.

Students from many countries came to seek his advice. His writing had an enormous reputation in their day. His Institutiones Medicae (1708) and Aphorismi de Cognoscendis et Curandis Morbis (1709) were enormously successful, and were published in many editions and translated into many languages. The method of instruction he introduced at Leyden became a model for Europe and later his pupils were to influence the teaching in Vienna, Germany and Britain.

Boerhaave described a neurological case of great interest in functional localisation. A beggar in Paris begged for money with his calvarium. How the skull cap had been removed is not specified but the beggar was a one man physiological laboratory. For a few coins he would allow the occipital area over his boney deficit to be pressed. The sparks and flashes of light experienced were described. For a larger amount of money, the benefactor could press on the brain more forcibly so that the beggar would drop unconscious to the ground.

Boerhaave was the first doctor to be honoured on a stamp for his medical works. Among the great physicians who studied under him were: the scientist van Haller, founder of the University of Gottingham; van Swieten, founder of the old Vienna School and Carl Linné (Linneaus) of Uppsala, founder of the Linnaean system of classification. Haller called Boerhaave "communis

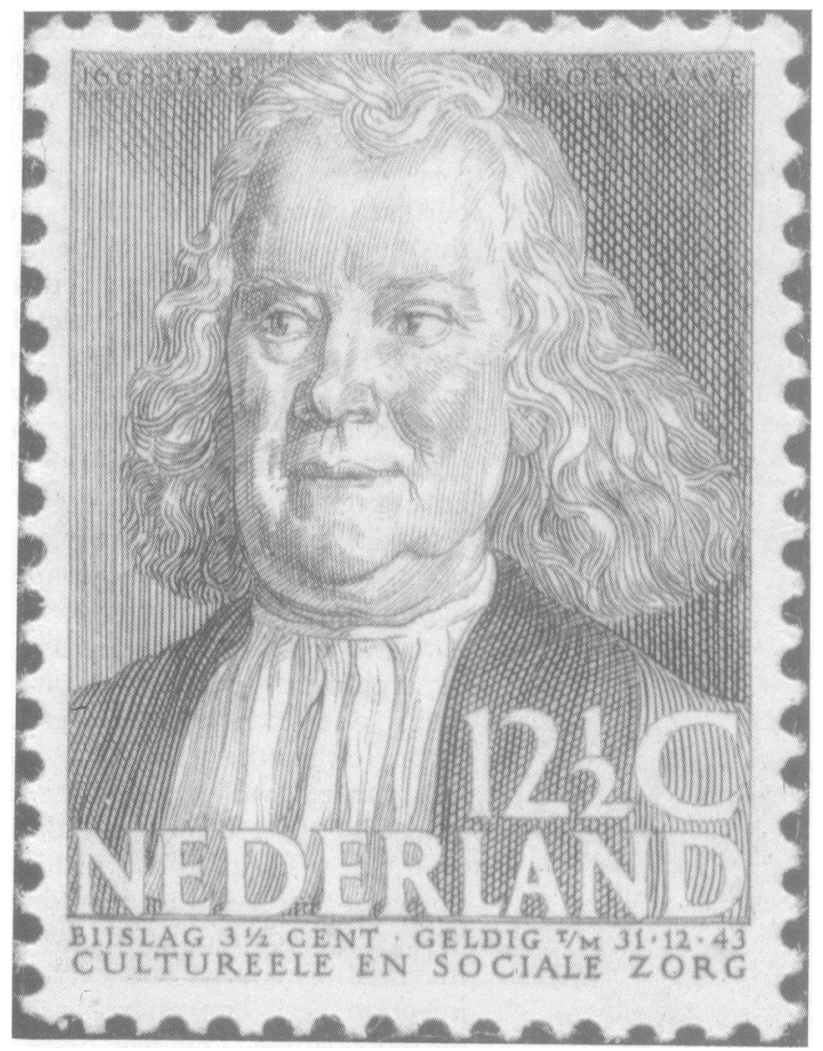

europae praeceptor"-the common teacher of Europe.

This stamp was issued by The Netherlands in 1928 (Stanley Gibbons 375a, Scott B107).

L F HAAS 